\title{
The AHP Model of Evaluation on Quality-Oriented Education in College English Teaching
}

\author{
Yanhong YUE
}

College of Foreign Languages, Wenzhou University, Wenzhou, China

\begin{abstract}
In this paper, following the characteristics and rules of English teaching, and by using pedagogical theory and the method of mathematical modeling we establish an Analytic Hierarchy Process model on the evaluation of quality-oriented education in college English teaching. And the computing results show that "classroom learning" is the most important, followed by "extra-curricular study", "English contests", "student research", "social practice", "teaching staff", "academic seminars", "teaching facilities", "community activities", which will be helpful to the reform of college English teaching.
\end{abstract}

Index Terms: Quality-oriented education, Evaluation, Analytic Hierarchy Process model, College English teaching

(C) 2012 Published by MECS Publisher. Selection and/or peer review under responsibility of the International Conference on E-Business System and Education Technology

\section{Introduction}

Since 1998, when China faced the challenges of the information technology revolution and the intense competition of economic globalization of the new century, the situation has changed substantially. China's higher education appeared so obsolete that some form of "major operation" needed to be immediately performed [1].

Nowadays college English teaching is facing new challenges. Quality-oriented education is based on the development of human potential and improvement of comprehensive abilities, and the goal lies in the enhancement of students' all-round development, morally, intellectually, physically and psychologically. The evaluation of quality-oriented education aims at understanding the level of students' development, affirming achievements, and discovering problems so that we can push forward the reform and development of qualityoriented education [2-3].

In 2004, the Ministry of Education of China promulgates "College English Curriculum Requirements" [4], which clearly states: The objective of college English teaching is to develop students' English language proficiency, especially listening and speaking skills, so that they can communicate effectively in their study,

* Corresponding author.

E-mail address: yanhongyue2010@gamil.com 
work and social interactions, enhance their self-study ability, and improve their overall cultural quality to meet the needs of China's social development and international exchange.

In this sense, the quality-oriented education in college English teaching involves listening comprehension, oral communication, reading comprehension, written expression and translation capacity, which implies that students should develop listening, speaking, reading, writing, translation and other English language skills through quality-oriented English teaching activities. While they practice verbal and written English to communicate effectively, students can improve their thinking, observation, attention, memory, imagination, and other capabilities [4-6].

In the teaching process, the knowledge system of English (including basic skills of listening, speaking, reading, writing and translation) makes the foundation of the quality-oriented college English teaching and other major courses are a necessary complement. Self-study ability is of the same importance for it guarantees the qualityoriented education. We also emphasize the application of English language, such as the writing of graduation thesis or research paper, which shows how well students grasp the language [7-8].

There are many researches on the evaluation of quality-oriented education, most of the studies focus on teaching phenomena and so on, but little attention has been paid to study on the qualitative study and quantitative study.

In this paper, based on the above discussions, we will use mathematical modeling to establish a new AHP model for the evaluation of quality-oriented college English teaching. For simplicity, this paper focuses on the evaluation of students' intellectual development.

The paper is organized as follows. In the next section, we establish the AHP evaluation model and present the results and analysis of the model. Finally, conclusions and remarks are given in Sec.III.

\section{The ahp model and results}

The Analytic Hierarchy Process (AHP) is a structured technique for dealing with complex decisions. It was proposed by T.L. Saaty —an American operations research professor in the 1970s [9-10]. Rather than prescribing a "correct" decision, the AHP helps the decision makers find the one that best suits their needs and their understanding of the problem.

Users of the AHP first decompose their decision problem into a hierarchy of more easily comprehended subproblems, each of which can be analyzed independently. The elements of the hierarchy can relate to any aspect of the decision problem - tangible or intangible, carefully measured or roughly estimated, well- or poorlyunderstood - anything at all that applies to the decision at hand.

Once the hierarchy is built, the decision makers systematically evaluate its various elements by comparing them to one another two at a time. In making the comparisons, the decision makers can use concrete data about the elements, or they can use their judgments about the elements' relative meaning and importance. It is the essence of the AHP that human judgments, and not just the underlying information, can be used in performing the evaluations.

The AHP converts these evaluations to numerical values that can be processed and compared over the entire range of the problem. A numerical weight or priority is derived for each element of the hierarchy, allowing diverse and often incommensurable elements to be compared to one another in a rational and consistent way. This capability distinguishes the AHP from other decision making techniques.

In the final step of the process, numerical priorities are calculated for each of the decision alternatives. These numbers represent the alternatives' relative ability to achieve the decision goal, so they allow a straightforward consideration of the various courses of action.

\section{A. The AHP model of the evaluation on quality-oriented college English teaching}

Based on a lot of readings of the quality-oriented college English teaching, we establish the hierarchical structure of the AHP model as follows: 


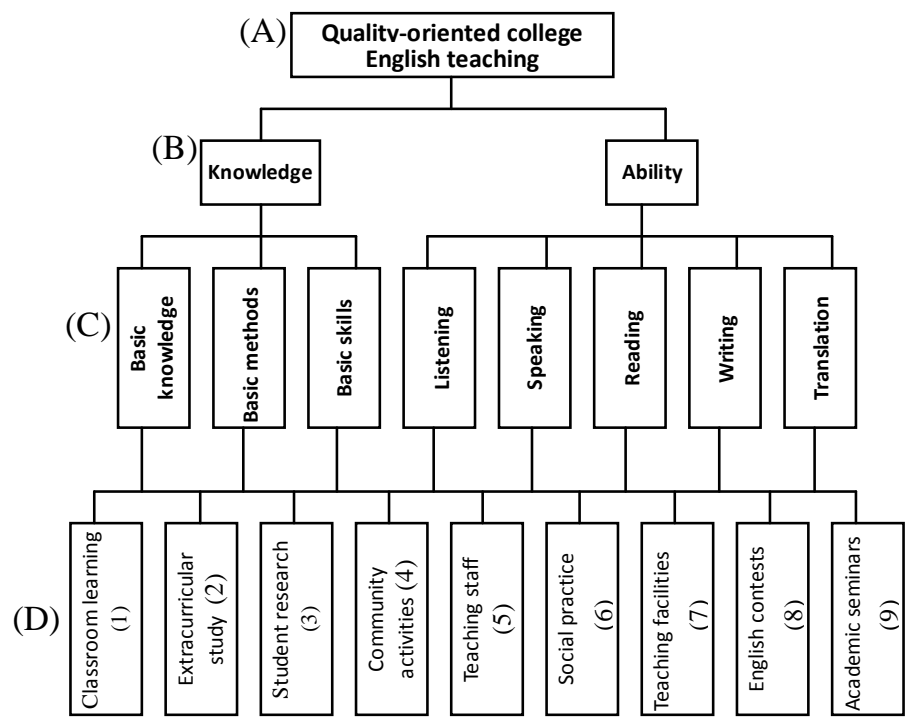

Figure 1. The hierarchical structure of the AHP model

Here, (A) stands for Goal; (B) Criteria; (C) Sub-criteria; (D) Alternatives.

$B$. The judgment matrix and the method of computing of the relative weights

According to the calculation steps of AHP model we establish priorities among the elements of the hierarchy and let teachers and students (a total of 9) make a series of judgments based on pairwise comparisons of the elements with 1-9 rating scale. See Table 1 about the fundamental scale for pairwise comparisons.

Table 1. The fundamental scale for pairwise comparisons

\begin{tabular}{|c|l|l|}
\hline $\begin{array}{c}\text { Intensity of } \\
\text { Importance }\end{array}$ & \multicolumn{1}{|c|}{ Definition } & \multicolumn{1}{c|}{ Explanation } \\
\hline 1 & Equal importance & $\begin{array}{l}\text { Two elements contribute equally to the } \\
\text { objective }\end{array}$ \\
\hline 3 & Moderate importance & $\begin{array}{l}\text { Experience and judgment slightly favor } \\
\text { one element over another }\end{array}$ \\
\hline 5 & Strong importance & $\begin{array}{l}\text { Experience and judgment strongly favor } \\
\text { one element over another }\end{array}$ \\
\hline 7 & Very strong importance & $\begin{array}{l}\text { One element is favored very strongly } \\
\text { over another, its dominance is } \\
\text { demonstrated in practice }\end{array}$ \\
\hline 9 & Extreme importance & $\begin{array}{l}\text { The evidence favoring one element } \\
\text { over another is of the highest possible } \\
\text { order of affirmation }\end{array}$ \\
\hline $\begin{array}{l}\text { Intensities of } 2,4,6, \text { and } 8 \text { can be used to express intermediate values. Intensities } \\
1.1,1.2,1.3, \text { etc. can be used for elements that are very close in importance. }\end{array}$ \\
\hline
\end{tabular}

Decision-makers answer questions repeatedly to determine the relative weights of the two factors $u_{i}$ and $u_{j}$, according to one criterion, such as, which is more important and how important they are, and score 1-9 on the rating weights. As for this scale, $n$ elements compared by a pairwise comparisons form a judgment matrix.

$A=\left(a_{i j}\right)_{n \times m}$.

For simplicity, we omit the results of the judgment matrix. 
On this basis, we calculate the relative weights of all the factors in one level to the highest level from the highest level to the lowest one by one, which is called the total rating of levels. If one level A contains $m$ factors $\mathrm{A}_{1}, \mathrm{~A}_{2}, \ldots, \mathrm{A}_{m}$, the rating of values of the whole level respectively are $a_{1}, a_{2}, \ldots, a_{m}$, another level $\mathrm{B}$ contains $n$ factors $\mathrm{B}_{1}, \mathrm{~B}_{2}, \ldots, \mathrm{B}_{n}$, and their rating weights for factor $\mathrm{A}_{j}$ respectively are $b_{1 j}, b_{2 j}, \ldots, b_{n j}$ (when $\mathrm{B}_{i}$ has nothing to do $\mathrm{A}_{j}$, then we take $b_{i j}=0$ ), and the relative weights of the total rating of level $\mathrm{B}$ is given in Table 2.

Table 2. The relative weights of the total rating of level B

\begin{tabular}{|c|c|c|c|c|c|}
\hline \multirow{2}{*}{ Level B } & $\mathrm{A}_{1}$ & $\mathrm{~A}_{2}$ & ....... & $\mathrm{A}_{m}$ & \multirow{2}{*}{$\begin{array}{l}\text { The weights of total } \\
\text { rating of level B }\end{array}$} \\
\hline & $a_{1}$ & $a_{2}$ & $\ldots \ldots$ & $a_{\mathrm{m}}$ & \\
\hline $\mathrm{B}_{1}$ & $b_{11}$ & $b_{12}$ & $\ldots \ldots$ & $b_{1 m}$ & $\sum_{j=1}^{m} a_{j} b_{1 j}$ \\
\hline $\mathrm{B}_{2}$ & $b_{21}$ & $b_{22}$ & $\ldots \ldots$ & $b_{2 m}$ & $\sum_{j=1}^{m} a_{j} b_{2 j}$ \\
\hline$\ldots \ldots$ & ...... & ....... & $\ldots \ldots$ & $\ldots \ldots$ & $\ldots \ldots$ \\
\hline $\mathrm{B}_{n}$ & $b_{n 1}$ & $b_{n 2}$ & $\ldots \ldots$ & $b_{n m}$ & $\sum_{j=1}^{m} a_{j} b_{n j}$ \\
\hline
\end{tabular}

\section{Results and analysis of the AHP model}

Now, the results are given as follows:

\section{1) The rating relative weights of Criteria (B) to Goal (A)}

Because the quality-oriented English teaching is a comprehensive reflection of both knowledge and abilities, which are equally important, and its rating weight is:

$y_{2-1}=(0.5,0.5)^{T}$.

2) The rating relative weights of Sub-Criteria (C) to Goal (A)

First we calculate the rating relative weights of Sub-criteria (C) to Criteria (B), and the result is:

$$
Y_{3-2}=\left(\begin{array}{cc}
0.5396 & 0 \\
0.2970 & 0 \\
0.1634 & 0 \\
0 & 0.1683 \\
0 & 0.3958 \\
0 & 0.2408 \\
0 & 0.1176 \\
0 & 0.0776
\end{array}\right) .
$$

Thus, the rating relative weights of Sub-criteria (C) to Goal (A) is:

$$
\begin{aligned}
Y_{3-1} & =Y_{3-2} \cdot Y_{2-1} \\
& =(0.1952,0.1074,0.0591,0.1074,0.2526,0.1537 .0 .0751,0.0495)^{T} .
\end{aligned}
$$

Similarly, we can obtain the rating relative weights of Alternatives (D) to Goal (A): $R=(0.2348,0.1688,0.1213,0.0362,0.1048,0.06405,0.0412,0.1291,0.0623)^{T}$, and that is, 
$r_{1}>r_{2}>r_{8}>r_{3}>r_{5}>r_{6}>r_{9}>r_{7}>r_{4}$

Here, the number of $1,2,3, \ldots$ are the same meaning as in the hierarchical structure of the AHP model in Sec. II (A).

And the results of the consistency test show that they all are less than 0.1 , and the results hold the judgment of satisfying consistency.

As a result, we can see that of all the factors affecting quality-oriented college English teaching, "classroom learning" accounts for the largest relative weight and therefore is most closely related to quality-oriented college English teaching, followed by "extra-curricular study," "English contests", "student research", "social practice", "teaching staff", "academic seminars", "teaching facilities", and "community activities".

\section{Conclusions and discussion}

In this paper, it is an attempt to evaluate quality-oriented college English teaching by AHP model. We obtain the results based on certain simplifications, but with the combination of qualitative and quantitative study, we can handle many problems that we cannot by traditional optimizing methods, which increases the effectiveness of decision-making, and therefore the results may provide some guidance for the evaluation of quality-oriented college English teaching.

Among various factors affecting quality-oriented college English teaching, "classroom learning" ranks the first, which illustrates that in today's information age, colleges as centers for human resource development are still playing an essential role in economic growth and development of the countries, and teachers have a positive impact on student learning. So we should attach great importance to classroom learning for it is the main source of information available to students.

It should be noted that "English contests" and "student research" rank in the third and fourth place respectively, which shows that we should also emphasize practical abilities, especially the application of English to the solution of problems. However, at present, these two aspects go unnoticed in universities, and especially, little attention is paid to "student research", which will be our priority of the reform of college English teaching in the future.

We should point out that human subjective factors have an effect on the establishment of AHP model and the process of the pairwise comparison, which should be compensated by the experts' judgments.

\section{References}

[1] L. Li, China's higher education reform 1998-2003: A summary, Asia Pacific Education Review, 5(1) 1422, 2004.

[2] M. M. Mashhadi, K. Mohajeri, and M. D. Nayeri, A quality-oriented approach toward strategic positioning in higher education institutions,

Int. J. Social Sci., 2(4)237-241, 2008.

[3] S. Michael, H. Qi, and J. H, Lesson from my fair lady about quality English language teaching, CELEA, 31(5)31-36, 2008

[4] The Ministory of Education of China, College English curriculum requirements (in Chinese), Foreign language teaching and research press, 2004.

[5] J. Cai, College English curriculum requirements and its consistency and foresight, Foreign Language World, 103(5)10-17, 2004.

[6] J. Chen, College English curriculum requirements: A theoretical understanding and appl ication (in Chinese), ETFLT, 100(12)46-50, 2004.

[7] D. Chen, Considerations on integration of all-round education into college English teaching (in Chinese), J. Yangzhou University, 13(3)84-86, 2009. 
[8] Y. Yang, The development of competence and quality in college English classroom teaching (in Chinese), Foreign language research, 149(4) 113-115, 2009.

[9] T.L. Saaty. A scaling method for priorities in hierarchical structures. J. Math. Psych., 15:234-281, 1977

[10] T.L. Saaty. The Analytic Hierarchy Process, Planning, Piority Setting, Resource Allocation. McGraw-Hill, New york, 1980.

[11]T.L. Saaty, Relative Measurement and its Generalization in Decision Making: Why Pairwise Comparisons are Central in Mathematics for the Measurement of Intangible Factors-The Analytic Hierarchy/Network Process. Rev. R. Acad. Cien. Serie A. Mat. 102 (2) 251-318, 2008. 